\title{
Assessment of Gas Yield Potentials of Selected Feedstocks in a Small Scale Anaerobic Digestion Plant: Case Study, L. Reule Bioenergy Plant, Uk
}

\author{
Chukwunonye Ezeah*, Amina Danjuma Stokes, Clive L. Roberts \\ Faculty of Science and Engineering, University of Wolverhampton, City Campus-South, Wulfruna Street, \\ Wolverhampton, UK, WVI ILY
}

\begin{abstract}
The aim of this research was to assess the anaerobic digestion (AD) process at the L. Reule Bioenergy Plant, a typical UK, small holder, on farm plant. The first objective was to determine whether the plant was using its waste products to achieve the maximum possible biogas output from its digestate. The second objective was to explore the main sources of gas: household, commercial, and blended waste sources. To achieve these objectives, multiple representative samples of waste samples were taken from the AD plant and were analysed in the laboratory. The data drawn from these analyses were interpreted and synthesised to determine the representative biogas yields. Further analysis was carried out using X-ray fluorescence (XRF) techniques to determine the elemental compositions of the feedstock/waste and digestate samples in order to determine other components that might be present. The results indicate that the dry digestate that is currently not used at the L. Reule Bioenergy Plant has potential for additional biogas yield. The study also found that household waste sample had the highest fat content, which indicates a higher biogas yield potential compared to commercial and blended waste samples.
\end{abstract}

Keywords: Anaerobic Digestion, Biogas Generation, Gas Yield Potential, Renewable Energy, UK,

\section{Introduction}

Research on energy generation from organic waste materials has tended to focus mainly on agricultural waste, such as maize and silage; more research is needed in the identification of quality feedstock from municipal solid waste (MSW) streams. This research attempts to provide empirical evidence on biogas yield potentials from a broad range of organic MSW samples. The study also determines which waste streams generate the most gas. The overall positive aspects of $\mathrm{AD}$ are that of energy recovery potential and diverting waste from landfills, thus reducing and mitigating environmental damage.

The L. Reule Bioenergy Plant is part of a family farm business that was originally based on raising pigs but has lately diversified into soft fruit production. To treat their waste materials effectively, the company acquired a medium sized anaerobic digestion (AD) plant with the capacity to treat between 25,000-30,000 tonnes of food waste per annum: 12,000 tonnes of household food waste, 12,000 tonnes of commercial waste (mostly from supermarkets), and approximately 1,000 tonnes of trade browns, generating approximately 1,300 kWe of energy (Fig. 1) in the process.

De-packing and initial processing of MSW feedstock into slurry takes place at the Four Ashes Material Recycling Facility. Using a vacuum tanker, the feedstock/waste is then brought to the AD plant at L. Reule. Water is added to the mixture, turning it into a product that can be fed into the digester. The plant generates approximately $1.3 \mathrm{MW}$ of electricity per year, which is enough to power up to 3,000 homes and businesses in the neighbouring village of Gnosall and the surrounding area, with potential savings equivalent to $23,000 \mathrm{t} \mathrm{CO}_{2}$ into the atmosphere.

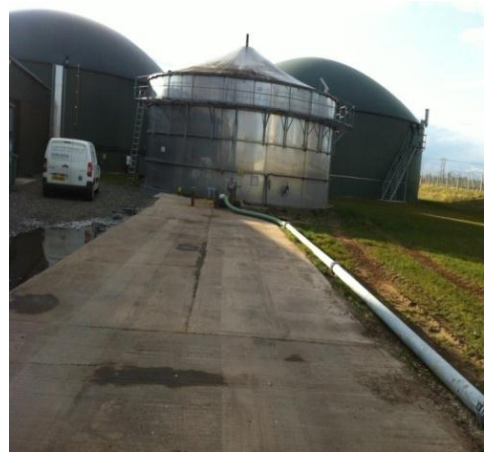

Fig 1: L. Reule Bioenergy Plant (Stokes, 2013) 


\subsection{Current Status of Anaerobic Digestion Technology in the UK}

$\mathrm{AD}$ technology is becoming a big business in the UK due to the gas potential and the potential to manage waste. There are currently over $100 \mathrm{AD}$ plants in the UK, Local authorities are responsible for structuring their waste management strategies to meet overall national and EU-wide objectives and targets. Local authorities vary in size, but the process of managing waste follows the same structure; that is, the size or scale of any waste management project should not obstruct the success or failure of any such project. According to Khalid (1), AD technology is now one of the most popular strategies adopted by local authorities in the UK for managing the organic fraction of their MSW stream. This strategy has helped reduce the amount of organic waste and, ultimately, the total volume of waste going to landfills (Fig. 2).

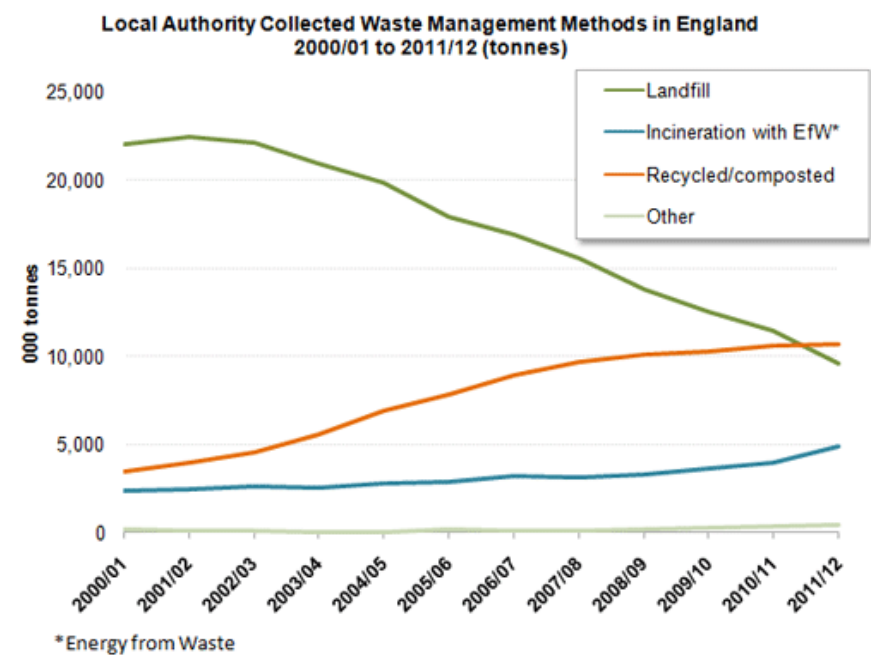

Fig 2: Local Authority collected waste graph (Defra, 2010)

$\mathrm{AD}$ refers to the microbial degradation of organic samples in the absence of oxygen (2). Two important byproducts of $\mathrm{AD}$ are digestates and biogas, which is a combination of methane and carbon dioxide. This makes the process a source of renewable energy. This biological process is also of global interest due to its efficiency in mitigating climate change through the reduction of greenhouse gas emissions and its potential as a sustainable alternative to the use of energy derived from fossil fuels (3). The accumulation of solid organic waste in almost all regions of the world has reached critical levels (1). Therefore, organic waste needs to be sustainably managed to prevent the depletion of natural resources, to minimise risks to human health, to reduce environmental burdens, and to maintain overall balance in the ecosystem (4). Raw, solid organic waste can be converted into biogas through $\mathrm{AD}$, but various factors, including substrate composition, influence the effectiveness of this process (5). Using the response surface methodology (RSM), Hafid et al. (6) determined the optimal conditions for organic acid production from the $\mathrm{AD}$ of kitchen waste. The results indicate that temperature and inoculum size are the most significant parameters affecting the bioconversion of kitchen waste to organic acids. An experiment verifying the estimated optimal conditions confirmed that RSM facilitates the optimisation of organic acid production from fermented kitchen waste (6). Long retention time, poor start-up performance, incomplete mixing, and accumulation of volatile fatty acids (VFAs) are the main disadvantages of solid-state fermentation. It therefore follows that developing feasible dry AD processes necessitates the evaluation of optimisation techniques and the identification of areas for improvement (7).

Biogas is produced using two core systems: dry and wet fermentation systems. Weiland (3) explored the present state of and the viewpoints on biogas production, highlighting the constraints encountered when using feedstock/waste and biochemicals. Such challenges affect the efficiency and reliability of microbial conversions, as well as gas yields. Weiland (3) explained that methane is produced within a narrow pH interval (about 6.5-8.5), with the optimum interval being 7.0 to 8.0. The process is severely inhibited when the $\mathrm{pH}$ level decreases below 6.0 or rises above 8.5. In a study by Liu et al. (8), the mixture of biogas and methane yields of food and green waste were determined using batch anaerobic digesters at mesophilic $35 \pm 2{ }^{\circ} \mathrm{C}$ and thermophilic $50 \pm 2{ }^{\circ} \mathrm{C}$. The mixture was of $50 \%$ green waste and $50 \%$ food waste, which was based on the volatile solids (VS) that were initially added to the reactors. Using thermophilic digestion tests with four different feed to inoculum (F/I) ratios (1.6, 3.1, 4.0, and 5.0) and mesophilic digestion conducted at one F/I (3.1), Liu et al. (8) showed that the F/I significantly affected the biogas production rate.

In a separate investigation, Hartmann and Ahring (9) found that waste streams such as food processing waste and ethanol silage are acidic, contain few naturally occurring microbes, and often lack the nutrients (nitrogen, trace elements, and vitamins) necessary for $\mathrm{AD}$. Other researchers have suggested co-digestion as a technique to enhance gas production $(5 ; 10)$. 
Weiland (3) stated that blending energy-dense feedstock/waste with livestock manure is a common practice in maximising biogas production; production increases because of the optimisation of nutrient levels and the improvement of buffering capacity $(9 ; 3)$ The waste types with high $\mathrm{C} / \mathrm{N}$ ratios more rapidly produce methane, serving as a reference for the likely operating retention time of a continuously fed digester (11). According to Weiland (3), all types of biomass can be used as substrates for biogas production as long as they contain carbohydrates, proteins, fats, and cellulose as the main components.

Karagiannidis et al. (12) studied the multi-criteria decision-making method, and their study suggests that maximising gas production does not depend solely on feedstock/waste quality, but also on the type of technology used in maximising gas production. The authors also reported that the most efficient technology for biogas production is the Drano technology, followed by Valorga technology (12). Their findings show that the former combines the advantages of a low-cost system and high energy recovery potential. However, Drano technology features a thermophilic process and is therefore not as attractive as Valorga technology, which offers both mesophilic and thermophilic operations (12). Only one new plant that uses Dranco technology has been constructed in the UK since 2000 (12).

Biogas/methane production can be quantified by keeping the volume constant and measuring the pressure increase, or volumetrically measured by providing constant pressure conditions, allowing for the measurement of gas volume. According to Li et al. (8), the effects of major operational parameters in maximising biogas yield are taking into account the solids content of the feedstock, the $\mathrm{C} / \mathrm{N}$ ratio, temperature, and inoculation on the performance. The author also noted that an increase in operating temperature can improve both production efficiency and biogas yield. Amongst other factors that can increase biogas yield, an AD digestate or leachate can be used as an inoculant and to decrease the solids content, although it has a negative impact on production efficiency.

Figure 3 shows biogas yield in accordance with feedstock/waste used. The figure suggests that feedstock/waste with fat exhibits the highest potential for gas production. Figure 3indicates that food waste has the highest gas production potential, whereas manure shows the least potential. If substrates are mixed, however, the potential for gas production is enhanced (10).

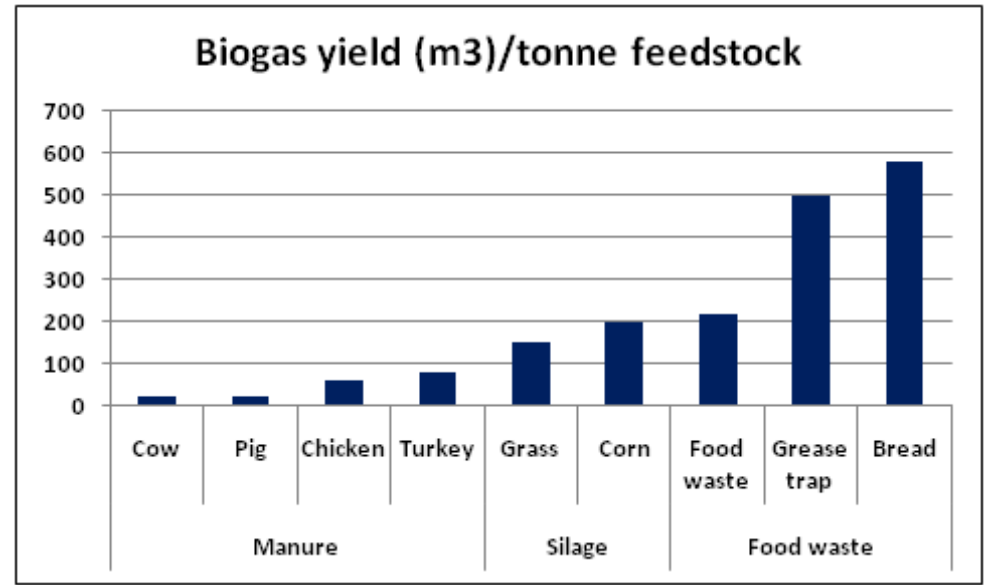

Fig 3: Biogas yield of feedstock/waste (Anaerobic Digestion Initiative Advisory Committee, 2009)

\section{Materials And Method}

This study, which has both a qualitative and a quantitative design, aims to identify which waste stream used at the L. Reule AD plant produced the highest amount of biogas per unit. Three samples, which were later re-categorised into five samples (Table 1), were collected from the plant for analysis at the University of Wolverhampton. The first sample was commercial waste collected from first and second-pass treatments (i.e. after the first pass, the waste underwent another round of treatment designed to produce finer waste samples). The second sample was household waste, dry digestate, and blended waste. The third sample was wet digestate. All samples were stored in sample containers prior to analysis. The entire batch of feedstock/waste samples was oven dried at $40^{\circ} \mathrm{C}$ for 48 hours and then homogenised before individual experiments were conducted. Data from the analyses were correlated, synthesised, and evaluated to determine which sample provided optimum biogas yields. 
Table 1: Categorised Feedstock Samples

\begin{tabular}{|l|l|}
\hline Sample Number & Description \\
\hline 1 & Dry digestate waste \\
\hline 2 & Household waste \\
\hline 3 & Blended waste \\
\hline 4 & Commercial waste first pass \\
\hline 5 & Commercial waste second pass \\
\hline
\end{tabular}

\subsection{Laboratory Analysis}

\subsubsection{Determination of Moisture Content (using BSI 2008 Standard)}

At the laboratory, empty foil containers were weighed before the feedstock samples were placed in them. The containers were weighed again with the samples in them to determine the wet weight, and then they were placed in the oven for 48 hours at a constant temperature of $40^{\circ} \mathrm{C}$ for drying. After 48 hours, each ovendried sample was weighed again to establish the moisture content.

Calculation for moisture content $(\mathrm{Mc})$ :

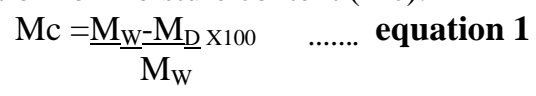

$\mathrm{Mw}=$ Mass wet

$\mathrm{M}_{\mathrm{D}}=$ Mass dry

\subsubsection{Determination of Nitrogen Content}

To determine the nitrogen content of the samples, each feedstock/waste sample was further homogenised so that it could pass through a sieve with apertures smaller than $1 \mathrm{~mm}$. Samples weighing $1 \mathrm{~g}$ were analysed using the Kjeldahl total nitrogen method (see Figure4).

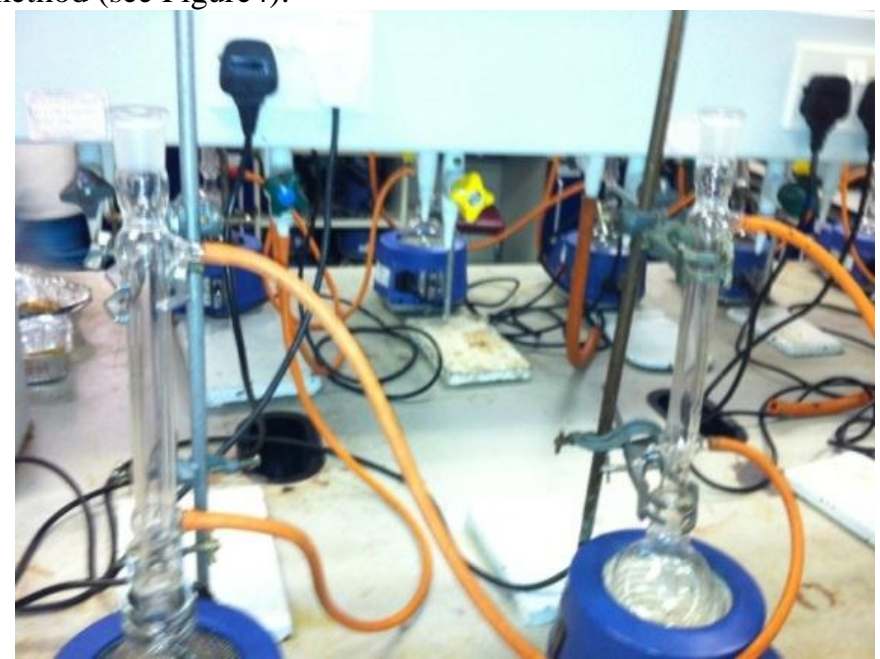

Fig 4: Experimental setup for nitrogen and carbon determination

\subsubsection{Fat Determination}

Feedstock samples were oven dried at $40^{\circ} \mathrm{C}$ for 48 hours and then homogenised before individual experiments were conducted. Homogenised samples were stored in sample airtight containers prior to analysis. Fat content was determined using a modified Soxhlet Randall method. This was achieved by omitting the wash altogether and leaving samples to stand for an hour and half instead of an hour as specified in the methods (Randall Method, British Standard, 2008). To determine the crude fat content in the feedstock samples, light petroleum ether was used as a reagent at a boiling range of $40^{\circ} \mathrm{C}$ to $60^{\circ} \mathrm{C}$. The waste samples were homogenised and sieved because they should have particle sizes lower than $1 \mathrm{~mm}$ and because the residue from evaporation should be less than $2 \mathrm{mg} / 100 \mathrm{ml}(13 ; 14)$.

\subsubsection{Gas Chromatography}

The result of the extraction of fat from the feedstock prompted further analysis using gas chromatography. The same material that was used to extract the fat in the feedstock by the Soxhlet method was then cooled before being subjected to further analysis. A gas chromatography machine was used to analyse gas extracted from fat samples for the purpose of identification (15). Statistical analysis was carried out using Microsoft Excel Software 2010 and GraphPad Prism statistical software version 6.0.1.298. 


\subsection{Result from Element Analysis}

\section{Results}

Results from elemental analysis indicate that the major elements found in the samples include $\mathrm{Ca}, \mathrm{Na}$, $\mathrm{Si}, \mathrm{K}, \mathrm{Fe}, \mathrm{P}$, and $\mathrm{Al}$ (Fig. 5). Analysis also indicated the presence of minor elements such as $\mathrm{Cd}, \mathrm{Pb}, \mathrm{Se}, \mathrm{CR}$, and $\mathrm{Hg}$, which are toxic to humans.

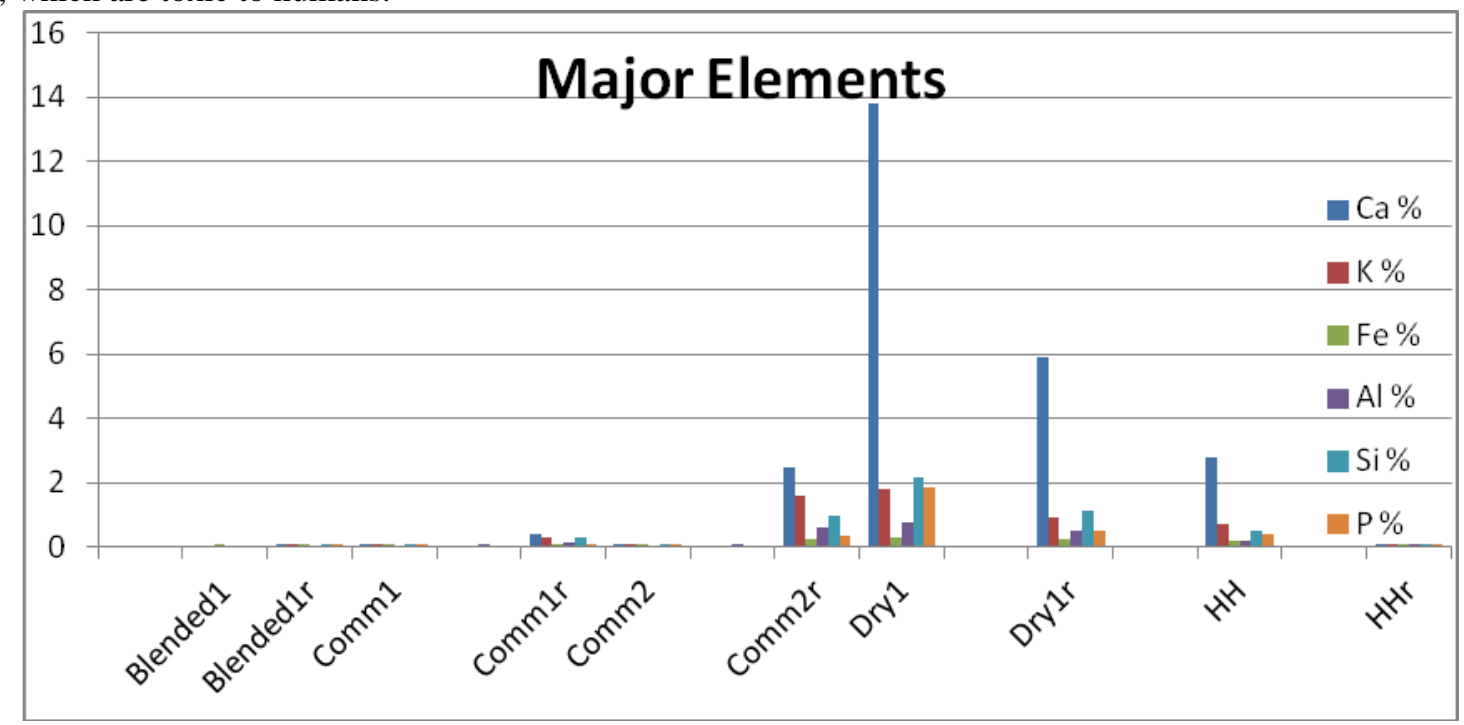

Fig 5: Major elements found in feedstock samples

Table 2: Fat content of five samples

\begin{tabular}{|l|l|l|l|l|}
\hline Feedstock/waste & Empty crucible & $\begin{array}{l}\mathrm{M}_{\mathrm{O}} \\
(\mathrm{g})\end{array}$ & $\begin{array}{l}\mathrm{M}_{\mathrm{F}} \\
(\mathrm{g})\end{array}$ & $\begin{array}{l}\text { Result (\%) } \\
(\mathrm{g})\end{array}$ \\
\hline $\begin{array}{l}\text { Dry digestate } \\
\text { AD 1 }\end{array}$ & 1.4 & 117.7643 & 0.1659 & 14.3 \\
\hline $\begin{array}{l}\text { Household } \\
\text { AD 2 }\end{array}$ & 3.8 & 118.6129 & 0.6955 & 18.4 \\
\hline $\begin{array}{l}\text { Blended } \\
\text { AD 3 }\end{array}$ & 2.3 & 96.7552 & 0.3568 & 17.4 \\
\hline $\begin{array}{l}\text { Comm 1 } \\
\text { AD 4 }\end{array}$ & 4.5 & 101.5112 & 0.5388 & 11.1 \\
\hline
\end{tabular}

Mf $=$ Mass Final

$\mathrm{Mo}=$ Starting Mass

Sum $\%=\mathrm{M}_{\mathrm{F}} / \mathrm{M}_{\mathrm{O}} \times 100 \%$ equation 2

AD $1=0.2 / 1.4 \times 100 \%=14.3 \%$

AD $2=0.7 / 3.8 \times 100 \%=18.4 \%$

$\mathrm{AD} 3=0.4 / 2.3 \times 100 \%=17.4 \%$

$\mathrm{AD} 4=0.5 / 4.5 \times 100 \%=11.1 \%$

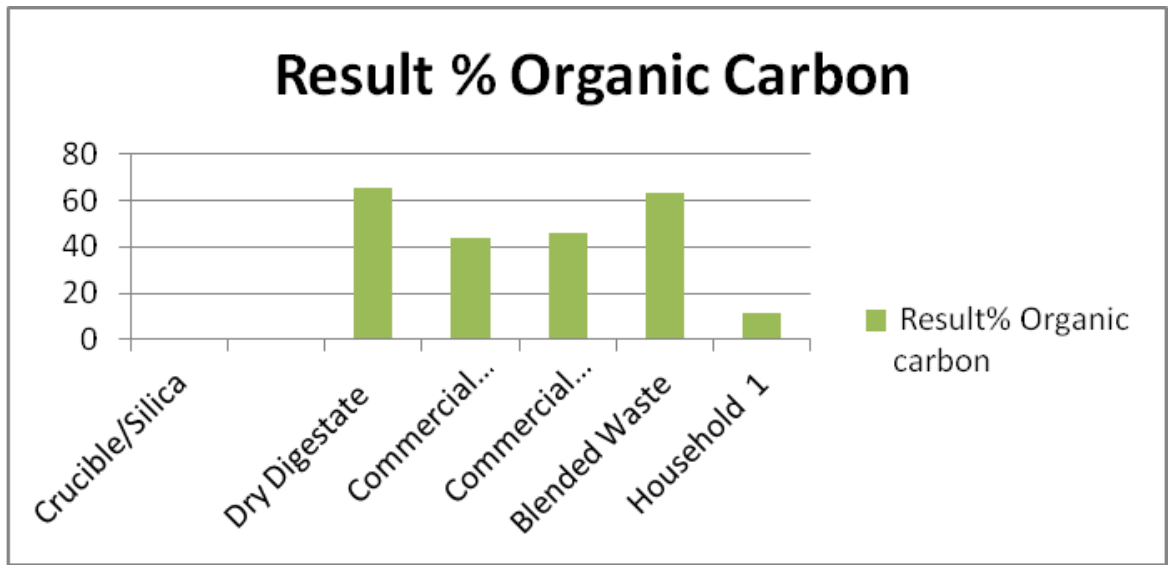

Fig 6: Carbon content of five feedstock samples 


\subsubsection{Determination of Organic Carbon Content of Feedstock by Titration Adapted from the Original Soil Method}

Feedstock samples were air dried and sieved. A potassium dichromate solution, $0.083 \mathrm{M} \mathrm{X5}$, was changed depending on the sample composition. A ferrous ammonium sulphate solution, $0.2 \mathrm{M}$ (composed of $20 \mathrm{~cm}^{3}$ of conc $\mathrm{H}_{2} \mathrm{SO}_{4}$ acid $+980 \mathrm{~cm}^{3}$ of water), was also used. The other materials employed in determining organic content were concentrated sulphuric acid and a diphenylamine indicator.

The feedstock samples were accurately weighed (i.e. to the fourth decimal place), and then about $0.1 \mathrm{~g}$ of each sample was placed in a small container. The sample was subsequently poured into a $250 \mathrm{~cm}^{3}$ round-bottomed flask. Anti-bumping granules ( 6 grains) were added to the flask to ensure smooth boiling. A standard potassium dichromate solution $\left(20 \mathrm{~cm}^{3}\right.$; orange yellow) was added to the granules using a pipette, and then $15 \mathrm{~cm}^{3}$ of concentrated sulphuric acid was carefully incorporated into the mixture using a measuring cylinder. The concentrated sulphuric acid was added a little at a time because this substance generates considerable heat. The flask was gently swirled to mix the contents.

Feedstock samples were air dried and sieved. A $0.083 \mathrm{M}$ X5 potassium dichromate solution was changed depending on the sample composition. A $0.2 \mathrm{M}$ ferrous ammonium sulphate solution, composed of $20 \mathrm{~cm}^{3}$ of conc $\mathrm{H}_{2} \mathrm{SO}_{4}$ acid $+980 \mathrm{~cm}^{3}$ of water, was also used. The other materials employed in determining organic content were concentrated sulphuric acid and a diphenylamine indicator.

The feedstock samples were accurately weighed (i.e. to the fourth decimal place), and roughly $0.1 \mathrm{~g}$ of each sample was placed into a small container. The sample was subsequently poured into a $250 \mathrm{~cm}^{3}$ round-bottomed flask. Anti-bumping granules (6 grains) were added to the flask to ensure smooth boiling. A standard potassium dichromate solution $\left(20 \mathrm{~cm}^{3}\right.$; orange-yellow) was added to the granules using a pipette, and then $15 \mathrm{~cm}^{3}$ of concentrated sulphuric acid was carefully incorporated into the mixture using a measuring cylinder. The concentrated sulphuric acid was added a little at a time because this substance generates considerable heat. The flask was gently swirled to mix the contents.

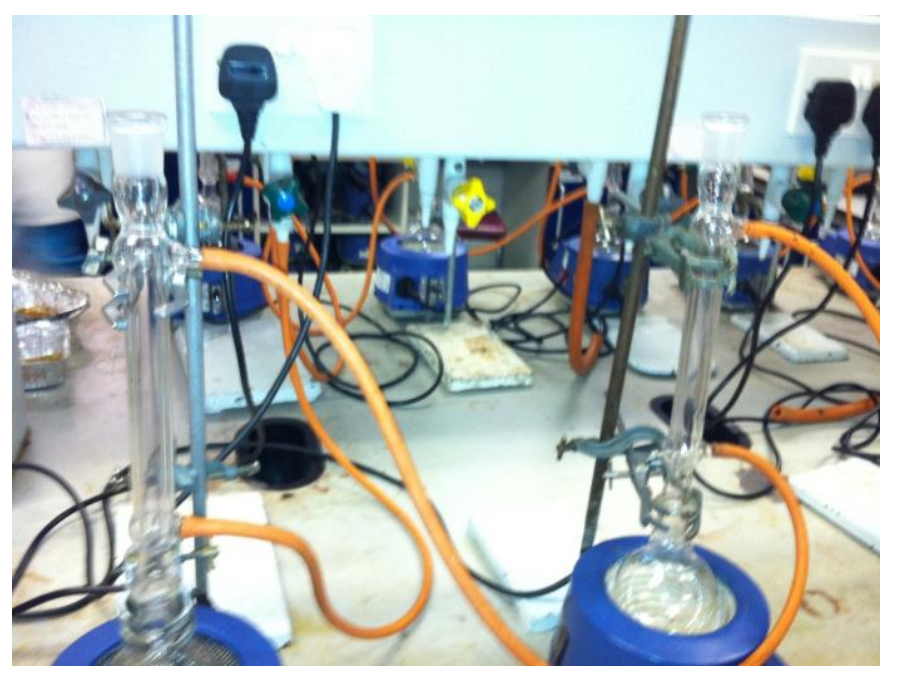

Fig 7 Experimental setup for carbon content determination

After ensuring that cooling water was flowing through the condenser, the mixture was refluxed (i.e. heated so that the mixture boils gently and the vapour condenses and drips back into the flask) for about 30 minutes (Fig 7). While the feedstock was being refluxed, a blank titration was prepared. Water $\left(100 \mathrm{~cm}^{3}\right)$ was placed in a conical flask, to which $30 \mathrm{~cm}^{3}$ of the standard potassium dichromate solution was added using pipette filler. Using a measuring cylinder, $20 \mathrm{~cm}^{3}$ of concentrated sulphuric acid was carefully added in small portions. Two drops of the diphenylamine indicator was also incorporated into the mixture. The solution turned dark brown (almost black), after which a burette was filled with a ferrous ammonium sulphate solution and run through the burette until no air remained below the tap. The burette was re-filled to the zero mark so that the base of the meniscus (the curved surface of the solution) was level with the zero mark. The ferrous ammonium sulphate solution was subsequently mixed with the acidified potassium dichromate in the conical flask by swirling, and the colour of the solution was closely observed. The colour changed from dark brown to deep blue to green, reflecting the end-point of titration. The volume of ferrous ammonium sulphate solution added was recorded and the burette was re-filled to the zero mark. 


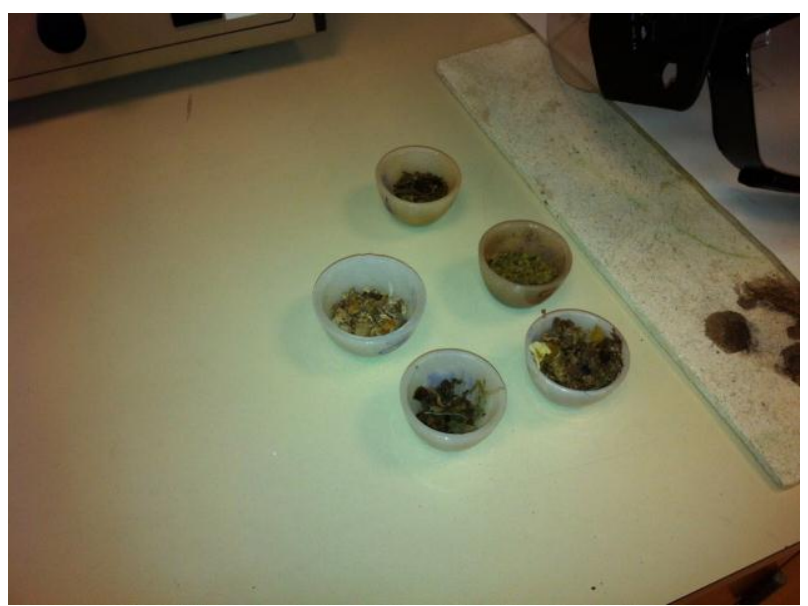

Fig 8: Pots of dried and semi-homogenised samples

When the feedstock sample had been refluxed for 30 minutes, the heat was switched off and the flask was allowed to cool. Water $\left(50 \mathrm{~cm}^{3}\right)$ was added, and the flask was thoroughly swirled and filtered to remove the feedstock. The filtrate was collected in a conical flask. The first flask had another $50 \mathrm{~cm}^{3}$ of water added, and its contents were filtered into the same conical flask. Two drops of the diphenylamine indicator and titrate with the standard ferrous ammonium sulphate solution were mixed into the flask. The volume added ( $V_{l}$ in Eq. (1)) was recorded once the colour changed from dark violet-blue to green. The amount of organic carbon in the feedstock ( $\mathrm{mg}$ of carbon per $\mathrm{g}$ of feedstock) was determined using Equation 3:

$$
\text { Organic carbon }\left(\mathrm{mg} \mathrm{g}^{-1}\right)=\frac{18 \times C \times V}{M} \times\left(1-V_{1} / V_{2}\right), \quad \ldots \text { equation } 3
$$

where $C$ is the concentration of potassium dichromate $(0.083 \mathrm{M}), V$ denotes the volume of potassium dichromate $\left(10 \mathrm{~cm}^{3}\right)$, and $M$ represents the mass of feedstock (in units of g). $V_{l}$ and $V_{2}$ are the volumes of ferrous ammonium sulphate from the titrations.

Table 3: Total nitrogen content of samples

\begin{tabular}{|l|l|}
\hline Sample Number & Total Kjeldahl nitrogen (TKN), mg/l \\
\hline Blended & 10.2 \\
\hline Commercial 1 & 7.3 \\
\hline Commercial 2 & 8.2 \\
\hline Household & 9.4 \\
\hline Dry digestate & 5.1 \\
\hline
\end{tabular}

\section{Discussions}

This study found that of all the waste/feedstock analysed, household waste had the greatest amount of gas potential. This was found through various experiments carried out with the sole purpose of maximising the gas potential using treated waste to be fed into the $\mathrm{AD}$ plant.

To determine where the most gas can be realised, each aspect of the feedstock/waste was analysed for the following properties: loss in ignition, moisture content measured, dry matter, organic dry matter, crude fat, and crude protein. These properties are significant in the determination of gas potential. The elemental compositions of each feedstock were analysed using X-ray fluorescence (XRF) techniques. This was done to assess other potential properties in each waste stream.

The dry matter determination procedure found that the dry matter of each waste stream was as follows: $0.4 \%$ in the dry digestate, $0.6 \%$ in the household waste, and $1.3 \%$ in the blended waste. The commercial waste first pass was $0.9 \%$ and the commercial waste second pass was $0.9 \%$, which indicates that the household waste had the driest matter. The results obtained from the determination of fat content in the dry digestate (Table 2) showed $14.3 \%$ fat in that particular waste stream. The fat content was as follows: $14.3 \%$ in the dry digestate, $18.4 \%$ in the household waste, $17.4 \%$ in the blended waste, and $11.1 \%$ in the commercial 1 stream. Hence, the fat content in the household waste was greater than in the other waste streams, and the commercial waste first pass had the least amount of fat. Thus, it can be assumed that household waste can be a significant source of gas potential, which supports the current theory (16.) based on agricultural and food waste, which suggests that feedstock/waste with fat, has the most gas potential. Section 3 shows fat was subjected to cooling and then used for further analysis via gas chromatography. The concentration of the fat content in the bottles differed considerably. Only four samples out of the five waste streams collected were analysed as a result of resource constraints The presence of fat is an important indicator of gas yield potentials, but the type of fat that was present from GC analysis requires further investigation, which is beyond the scope of present investigation. 
The trace element results show that the dry digestate had significantly more of the major elements than the other streams. Therefore, the L. Reule Bioenergy Plant could use this product effectively by making use of dry digestate, which has marketable enzymes or nutrients that could be mixed with other feedstock/waste products with fewer nutrients, as observed by Shanmugam and Horan (11). Hence, this could further aid the AD process, which would maximise the gas potential of the L. Reule Bioenergy Plant. The usefulness of co-digestion has been observed by Anjum et al (5), who suggested mixing melon with a combination of feedstock/waste to achieve a higher gas production.

The dry digestate had the following element levels, from highest to lowest: sodium level was 7.9 and 5.39 compared to the other feedstock which were low ( $(\mathrm{Na})$,(silicon $(\mathrm{Si})$, sulphur $(\mathrm{S})$, phosphorus, 1.834 and 0.478 aluminium (Al), and magnesium $(\mathrm{Mg}) .0 .429$ and 0.154 These figures were the same for the commercial 2 measurement, except for the magnesium and phosphorus levels. The dry digestate seemed to have the highest level of sodium, magnesium, and phosphorous, which are useful components in soil nutrients and fertilisers. This finding agrees with other digestate analyses. According to Tambone et al. (17), digestate has higher phosphorus $(\mathrm{P})$ and potassium $(\mathrm{K})$ concentrations than that of composts, which makes it suitable for supplementing the macronutrients in soil. Makádi (18) also noted that although numerous papers have dealt with the importance of the quantity and quality of basic materials in biogas production, data regarding the use of digestate as a plant nutrient source are lacking.

This analysis found that there are more compounds in the dry digestate samples than in the other samples. There is more chlorine, potassium, and calcium in the dry digestate than in the other waste which further emphasises the usefulness of dry digestates in the AD process. The implication of this is the dry digestates from the L. Reule plant could be further exploited by putting it through the digester multiple times until all energy within it is fully used.

The XRF/trace element results show that dry digestate had some useful elements for soil remediation, agricultural land improvement, and gas production. Due to time constraints, it was not possible to fully analyse each aspect of the numerous elements found. This requires additional exploration as to what each element signifies as a product suitable for gas production or fertiliser, and whether there is enough of the trace element to make this result significant. There are also minor elements in the waste streams, such as cadmium (Cd) and mercury $(\mathrm{Hg})$, that could be deemed dangerous for humans, plants, and animals if introduced to the soil. It is important to be aware of the amount of such elements that can be considered as harmless if introduced to the land as fertiliser.

Thermal gravimetric analysis (TGA) indicates the presence of other compounds being lost at different points of the analysis. The blended loss on ignition (LOI) was 94. This derivative indicates the presence of other compounds as losses occurred at different points of the analysis. For the purposes of this research, only the LOI was included in the TGA due to time constraints; therefore, further work needs to be carried out to identify burnt-out compounds within the different waste stream. The LOI was between $94 \%-99.9 \%$, which indicates a feedstock/waste with a potential gas yield due to the $\mathrm{CO}_{2}$ content.

The carbon and nitrogen analyses were the only ones that were conducted twice: once in May and once in July. The results conclude that there was no significant difference in either sample, despite the length of time between waste collections. This could indicate that the waste composition might not change significantly from week to week, even though there was no quantitative data available at the time this research was conducted. This shows that the waste collected at the plant may not have significant differences in components from week to week.

\section{Conclusions}

The aim of this study was to identify and evaluate the major sources of gas in waste samples and to enhance the waste treatment processes used by the L. Reule Bioenergy Plant. This research determined the company's primary sources of gas: households, commercial, and blended waste sources. The study analysed the moisture content, dry matter, and LOI in the feedstock/waste, which are important factors in gas production. Organic carbon, nitrogen, fat, and protein contents from individual feedstock/waste were also analysed. The study thus identified the feedstock/waste with the highest potential for yielding gas. The conclusions drawn from GC analysis and Randall method suggest that household waste has the most fat in its waste stream; therefore, it could have the most gas potential. In addition, dry digestate seems to have the most calcium of all the waste streams, which is also an important factor in gas production.

The results suggest that L. Reule could improve its current practices to maximise the gas potential from waste as the TGA showed that it has some burnt-out elements. This research achieved its objectives. However, due to resource and time constraints, further analysis to provide a better understanding of the contribution of each waste stream and its individual gas yield potential could not be carried out 


\subsection{Recommendations:}

1. Based on the analyses carried out, it can be recommended that the L. Reule Bioenergy Plant re-evaluate the use of its digestate, both as an inoculant and as a mixture with other feedstock.

2. Additionally, household waste samples could be co digested with dry digestate to maximise and increase L.

Reule's gas production.

\section{References}

[1]. Khalid, A., Arshad, M. and Anjum, M. et al. (2011) The anaerobic digestion of solid organic waste. Waste Management [online], 31 (8): 1737-1744

[2]. Kranert, M., Kusch, S. and Huang, J. et al. (2012) “Anaerobic digestion of waste.” In Waste to Energy. Springer

[3]. Weiland, P. (2010) Biogas production: current state and perspectives. Applied Microbiology and Biotechnology, 85 (4): 849-860

[4]. Kim, D. and Oh, S. (2011) Continuous high-solids anaerobic co-digestion of organic solid wastes under mesophilic conditions. Waste Management [online], 31 (9): 1943-1948

[5]. Anjum, M., Khalid, A. and Mahmood, T. et al. (2012) Anaerobic co-digestion of municipal solid organic waste with melon residues to enhance biodegradability and biogas production. Journal of Material Cycles and Waste Management [online], 14 (4): 388-395

[6]. Hafid, H., Rahman, N. and Abd-Aziz, S. et al. (2011) Enhancement of organic acids production from model kitchen waste via anaerobic digestion. African Journal of Biotechnology [online], 10 (65): 14507-

[7]. Jha, A., Li, J. and Nies, L. (2011) Research advances in dry anaerobic digestion process of solid organic wastes. African Journal of Biotechnology [online], 10 (65): 14242-14253

[8]. Li, Y., Park, S.Y. and Zhu, J. (2011) Solid-state anaerobic digestion for methane production from organic waste. Renewable and Sustainable Energy Reviews [online], 15 (1): 821-826

[9]. Hartmann, H. and Ahring, B.K. (2005) Anaerobic digestion of the organic fraction of municipal solid waste: influence of codigestion with manure. Water Research [online], 39 (8): 1543-1552

[10]. Angelidaki, I. and Ellegaard, L. (2003) Codigestion of manure and organic wastes in centralized biogas plants. Applied Biochemistry and Biotechnology, 109 (1-3): 95-105

[11]. Shanmugam. P. and Horan, N.J. (2009) Simple and rapid methods to evaluate methane potential and biomass yield for a range of mixed solid wastes. Bioreseource Technology, 100, 471-474

[12]. Karagiannidis, A. and Perkoulidis, G. (2009) A multi-criteria ranking of different technologies for the anaerobic digestion for energy recovery of the organic fraction of municipal solid wastes. Bioresource Technology, 100 (8): 2355-2360

[13]. Osborne, B.G., Fearn, T. and Randall, P. G. (1983) Measurement of fat and sucrose in dry cake mixes by near infrared reflectance spectroscopy. International Journal of Food Science and Technology, 18 (5): 651-656

[14]. Thiex, N.J., Anderson, S. and Gildemeister, B. (2003) Crude fat, hexanes extraction, in feed, cereal grain, and forage (Randall/Soxtec/Submersion method): Collaborative study. Journal of AOAC International [online], 86 (5): 899-908

[15]. Zhang, R., El-Mashad, H.M. and Hartman, K. et al. (2007) Characterization of food waste as feedstock for anaerobic digestion. Bioresource Technology [online], 98 (4): 929-935

[16]. Gatta, G., Gagliardi, A. and Soldo, P. et al. (2013). Grasses and legumes in mixture: an energy intercropping system intended for anaerobic digestion. Italian Journal of Agronomy, 8 (1): e7

[17]. Tambone, F., Scaglia, B. and D'Imporzano, G. et al. (2010) Assessing amendment and fertilizing properties of digestate from anaerobic digestion through a comparative study with digested sludge and compost. Chemosphere, 81 (5): 577-583

[18]. Makádi, Marianna, et al. (2007) Effect of a biogas-digestate and bentonite on some enzyme activities of the amended soils. Cereal Research Communications, 35 (2): 741-744 